AUDIT

\title{
Completion of the audit cycle: standardised nurse-led information for patients
}

\author{
R A Sharma, L Furber, L D Granger, C Archdeacon, G Thomas, R P Symonds
}

Postgrad Med J 2003;79:652-654

See end of article for authors' affiliations ......................

Correspondence to: Dr Ricky Sharma,

Oncology Department, University Hospitals of Leicester, Leicester Royal Infirmary, Leicester LE1 $5 \mathrm{WW}, \mathrm{UK}$;

ras20@le.ac.uk

Submitted 28 May 2003 Accepted 2 June 2003
Background: It is increasingly accepted that patients want information about their proposed treatment, and that provision of such information may alleviate fear and may improve the process of obtaining informed consent. It is not yet clear what form such information should take.

Objective: Based on differences shown previously between patients receiving standard treatment and those in clinical trials, a system of routine appointments with a chemotherapy nurse at least one day before the patient offered consent to treatment was established for all patients receiving chemotherapy in Leicestershire, at which time patients were given standardised written information regarding outpatient chemotherapy and specific drugs.

Method: In order to complete the audit cycle, the previous questionnaire study was repeated.

Results: From 160 questionnaires distributed, 131 complete replies were received. Compared with the previous audit, a significantly higher proportion of patients receiving standard chemotherapy remembered being given written information about chemotherapy from a nurse before starting their treatment and remembered signing a consent form. The significant difference in feelings of involvement in the decision to have chemotherapy between patients receiving standard chemotherapy and those in clinical trials detected in the previous audit was no longer detectable, suggesting the clinical effectiveness of the intervention performed.

Conclusion: Implementation of nurse-led appointments with provision of standardised information before formal consent being taken should be studied further for its potential to improve patients' involvement in medical decision making.
$\mathrm{D}$ ecision making in medicine consists of a doctor's offer of treatment, based on the current evidence base, and the patient's consent to that offer. ${ }^{1}$ An extreme example of such decision making is provided by the diagnosis of cancer, when potentially depressing statistics about survival and low probabilities of response to treatment must be combined with consideration of the potential toxicity of chemotherapy. Studies have claimed that $40 \%$ to $80 \%$ of newly diagnosed cancer patients wish to be involved in decision making,,$^{2-4}$ but little is known about how best to provide relevant medical information to these patients for them to make an informed decision regarding consent. ${ }^{5}$ Such research is particularly important in view of the increasing body of evidence suggesting that patients want more information about their proposed treatment, and that communication of such information may alleviate uncertainty and fear, ${ }^{6-10}$ even when the patient prefers to adopt a relatively passive role in decision making. ${ }^{3}$ The delivery of information to cancer patients by doctors and nurses has been defined as a "primary responsibility" in UK government initiatives, suggesting that written or other forms of information should supplement verbal communication in some cases. ${ }^{11}$ National quality guidelines for the content and delivery of information to patients have been published, ${ }^{12}$ but the effect on patient satisfaction of written information that meets these criteria has not been studied.

In a previous audit, we studied by questionnaire the general level of satisfaction with information patients had received before giving consent to chemotherapy, comparing patients receiving standard chemotherapy with those receiving chemotherapy in the context of a clinical trial. ${ }^{13}$ Involvement in the decision to have chemotherapy was encouragingly high, although patients in clinical trials were significantly more likely than other patients to feel they had taken part in the decision to have chemotherapy. Our interpretation of the results was that the greater feeling of involvement may have pertained either to the closer involvement of trial nurses in obtaining consent or to the written information routinely offered in clinical trials.

In order to equilibrate the amount of written information offered by nurses to non-trial and trial patients in our department, a system of routine appointments was established for all patients being offered chemotherapy. By equilibrating the amount of written information offered to non-trial and trial patients by a chemotherapy nurse, and subsequently repeating the questionnaire study, we hoped to complete the audit cycle.

\section{METHODS}

Further to the previous study, ${ }^{13}$ a system of routine appointments with a chemotherapy nurse was established for all patients receiving chemotherapy in Leicestershire from July 2001. At least one day before the patient offered consent to treatment, during a nurse-led consultation, patients were given standardised written information ${ }^{14}$ regarding outpatient chemotherapy in general and the specific drugs being considered.

In a fortnight period during August 2002, all patients receiving chemotherapy in Leicestershire were offered the questionnaire by the clinic clerk. This number of patients was above the minimum required for results to reach statistical significance, allowing for the small proportion of patients in clinical trials (approximately 25\% at this hospital). The questionnaire consisted of 10 basic descriptive questions about background and previous treatment, followed by the eight multiple choice questions to assess patient satisfaction as in the previously published questionnaire, ${ }^{13}$ plus four extra questions shown in table 1. Space was offered in the 
Table 1 Responses to questions not included in the original audit (\% total respondents)

\begin{tabular}{|c|c|c|c|c|}
\hline Question & Response options & $\begin{array}{l}\text { Clinical trial/ } \\
\text { patients " } \mathrm{C} \text { " } \\
\text { ( } \mathrm{n}=40)\end{array}$ & $\begin{array}{l}\text { Other patients } \\
(n=91)\end{array}$ & $\begin{array}{l}\text { Significance of } \\
\text { comparison of " } \mathrm{C} \text { " } \\
\mathrm{v} \text { others }\end{array}$ \\
\hline $\begin{array}{l}\text { Do you feel you were told } \\
\text { enough about your disease } \\
\text { before starting chemotherapy? }\end{array}$ & $\begin{array}{l}\text { Yes } \\
\text { Partially } \\
\text { No } \\
\text { Definitely not }\end{array}$ & $\begin{array}{l}21(52) \\
15(38) \\
4(10) \\
0\end{array}$ & $\begin{array}{l}69(76) \\
13(14) \\
3(3) \\
2(2)\end{array}$ & NS \\
\hline $\begin{array}{l}\text { Who do you think would be } \\
\text { the easiest person to talk to } \\
\text { about your current } \\
\text { chemotherapy? }\end{array}$ & $\begin{array}{l}\text { Consultant } \\
\text { Hospital nurse } \\
\text { Junior doctor } \\
\text { GP } \\
\text { Community nurse } \\
\text { Other* }\end{array}$ & $\begin{array}{l}17(43) \\
21(53) \\
1(3) \\
1(3) \\
0 \\
0\end{array}$ & $\begin{array}{l}35(38) \\
34(37) \\
2(2) \\
3(3) \\
3(3) \\
14(15)\end{array}$ & $\mathrm{P}<0.05$ \\
\hline $\begin{array}{l}\text { If you ever felt you wanted } \\
\text { to stop the chemotherapy, } \\
\text { who would you tell first? }\end{array}$ & $\begin{array}{l}\text { Consultant } \\
\text { Hospital nurse } \\
\text { Junior doctor } \\
\text { GP } \\
\text { Community nurse } \\
{ }^{*} \text { Other }\end{array}$ & $\begin{array}{l}30(75) \\
9(23) \\
1(2) \\
0 \\
0 \\
0\end{array}$ & $\begin{array}{l}54(59) \\
25(27) \\
2(2) \\
6(7) \\
1(1) \\
3(3)\end{array}$ & NS \\
\hline $\begin{array}{l}\text { Do you feel you are in } \\
\text { expert hands? }\end{array}$ & $\begin{array}{l}\text { Yes } \\
\text { No } \\
\text { Don't know } \\
\text { Not answered }\end{array}$ & $\begin{array}{l}39(98) \\
0 \\
0 \\
1(2)\end{array}$ & $\begin{array}{l}86(96) \\
0 \\
4(4) \\
0\end{array}$ & NS \\
\hline
\end{tabular}

questionnaire for patients to include their own comments. If the patient was currently in a clinical trial, recorded in the patient list before every clinic, a "C" was recorded on the back of the questionnaire by the clinic clerk before handing it to the patient. Anonymous replies were collected the same day in a labelled box in the waiting area of the chemotherapy suite, and responses analysed using simple descriptive statistics and Fisher's exact test on Minitab version 13.0 software package.

\section{RESULTS}

Excluding repeat visits, 191 patients attended the department for chemotherapy during the study period. Of these patients, 169 were asked to complete the questionnaire; the others were missed accidentally by the clinic clerk. A total of 160 patients accepted the document, and 131 replies were received either wholly or partially completed (82\% response rate). Characteristics of the respondents are shown in table 2 . A significantly greater proportion of patients remembered receiving written information and remembered meeting a

\section{Table 2 Characteristics of respondents}

\begin{tabular}{ll}
\hline Characteristic & No of patients \\
\hline Gender & 63 \\
Male & 68 \\
Female & \\
Marital status & 97 \\
Married & 29 \\
Live alone & 5 \\
Other & $37^{*}$ \\
Received prior chemotherapy & 35 \\
Received prior radiotherapy & $104^{*}$ \\
Understand the term "clinical trial" & $124^{*}$ \\
Met a nurse before consent & $117^{*}$ \\
Received written information before & \\
consent & \\
\hline
\end{tabular}

Asterisks indicate that the proportion of respondents answering the question affirmatively was significantly different $(p<0.05)$ than in the previous audit. $^{13}$ chemotherapy nurse before giving consent to treatment than in the previous audit. ${ }^{13}$ The mean age was 60 years (range 30 82 ) and the mean distance of home address from the hospital was 12 miles (range 0.5-176), with no significant differences between clinical trial (" $\left.\mathrm{C}^{\prime \prime}\right)$ and non-trial patients.

Comparisons were made between clinical trial patients $(\mathrm{n}=40)$ and non-trial patients $(\mathrm{n}=91)$. Clinical trial and non-trial patients were equally likely to have received prior chemotherapy. In the previous audit, patients in clinical trials were more likely to feel that they had taken part in the decision to have chemotherapy $(p=0.05)$ than patients receiving standard treatment. ${ }^{13}$ Reaudit did not detect a difference between the two groups, with a positive response from $73 \%$ of all respondents. Similar to the previous audit, fewer than $20 \%$ of respondents in both groups would have preferred greater involvement. Contrary to the previous study, in which only $56 \%$ of non-trial patients remembered signing a consent form, $74 \%$ of non-trial respondents remembered this event in the reaudit (difference between audits significant at $\mathrm{p}<0.01$ ). In the reaudit, $31 \%$ of non-trial respondents thought a hospital nurse was the person who had given them the most information about their treatment; $4 \%$ of non-trial patients listed a hospital nurse as the chief informant in the previous study (difference between audits significant at $\mathrm{p}<0.001)$. Within the context of clinical trials, $27 \%$ listed a hospital nurse as the chief informant, a similar proportion to the previous audit. Reassuringly, $87 \%$ of all respondents felt satisfied or very satisfied with the information about side effects given to them before starting chemotherapy, with no significant differences between the trial and non-trial patients. This encouraging finding was reflected in the extra questions included in the reaudit (table 1).

\section{DISCUSSION}

The use of quantitative scales to measure qualitative values is likely to represent a blunt instrument; however, the statistically significant results presented above provide some feedback for health care professionals and patient groups. 
In this reaudit, equilibration of written information received by patients receiving standard chemotherapy and those in clinical trials appeared to result in annulment of the significant difference in feelings of involvement in the decision to have chemotherapy detected in the first audit, suggesting the clinical effectiveness of the intervention performed. Although retrospective studies are limited by poor patient recall for information regarding cancer, as low as $25 \%$ in some studies, ${ }^{15}$ it is not known whether written information improves or inhibits such recall. Despite this limitation, the clinical effectiveness demonstrated appears favourable.

It is also not known what form written information should take in order to be optimal for patients. A study of 25 factsheets offered to patients undergoing prostate surgery found a significant mismatch between the leaflets offered and the information patients actually wanted. ${ }^{16}$ One review of written information offered to patients with hypertension has suggested that a wide range of leaflets should be made available to patients, so that they may choose the information best suited to their circumstances. ${ }^{17}$ This approach may be limited by the varying levels of information patients already have about their diagnosis or treatment, and it depends on patients having the time and ability to choose the appropriate leaflet. Sensibly, it has been suggested that assessing patients' information needs should play a larger part in the education of health professionals, both at undergraduate and continuing educational levels. ${ }^{18}$ As written information is developed, albeit conforming to national guidelines, ${ }^{12}$ quality assessment and continual updating should be performed, perhaps using instruments developed specifically for this purpose. ${ }^{19}$ Feedback may be obtained from patients by simple questionnaire, or preferably by in-depth interview studies. The relevance of language and cultural differences should also be noted in preparing appropriate information. ${ }^{20}$ In terms of the questionnaire study performed here, the level of satisfaction with the BACUP leaflets ${ }^{14}$ provided to patients appeared high.

The results of the reaudit do show that patients in clinical trials are significantly more likely to talk to a hospital nurse about their treatment than patients receiving standard treatment. This effect was detected in the original audit, ${ }^{13}$ and has not been influenced by the system of routine appointments implemented for patients receiving standard treatment. It is likely that the closer involvement of a named nurse in administering each cycle of treatment results in a favourable nurse-patient relationship in the clinical trial setting, as opposed to standard treatment at our centre when different nurses often administer treatment on different occasions.

In conclusion, the significant difference in feelings of involvement in the decision to have chemotherapy between patients receiving standard chemotherapy and those in clinical trials detected in the previous audit was no longer detectable in the reaudit, suggesting the clinical effectiveness of the intervention performed. Implementation of nurse-led appointments with provision of standardised information prior to formal consent being taken should be studied further for its potential to improve patients' involvement in medical decision making.

\section{ACKNOWLEDGEMENTS}

We thank Ian Fussey, consultant psychologist, and Francine Cheater, professor of nursing, for their critiques of drafts of the questionnaire.

\section{Authors' affiliations}

R A Sharma, L Furber, L D Granger, G Thomas, R P Symonds, Oncology Department, University Hospitals of Leicester, Leicester Royal Infirmary

C Archdeacon, Clinical Standards and Monitoring Department, University Hospitals of Leicester, Leicester General Hospital

\section{REFERENCES}

1 Downie RS. The value and quality of life. J R Coll Physicians 1999;33:378-81.

2 Cassileth B, Zupkis RV, Sutton-Smith K, et al. Information and participation preferences among cancer patients. Ann Intern Med 1980;92:832-6.

3 Beaver K, Luker KA, Owens RG, et al. Treatment decision making in women newly diagnosed with breast cancer. Cancer Nursing 1996;19:8-19.

4 Slevin ML, Stubbs L, Plant HJ, et al. Attitudes to chemotherapy: comparing views of patients with cancer with those of doctors, nurses, and general public. BMJ 1990;300:1458-60.

5 Arthur VAM. Written patient information-a review of the literature. J Adv Nurs 1995;21:1081-6.

6 Meredith C, Symonds P, Webster L, et al. Information needs of cancer patients in west Scotland: cross sectional survey of patients' views. BMJ 1996:313:724-6.

7 Audit Commission. What seems to be the matter? Communication between hospitals and patients. London: HMSO, 1993 (NHS report No 12).

8 Houts PS, Rusenas I, Simmonds MA, et al. Information needs of families of cancer patients: a literature review and recommendations. J Cancer Educ $1991 ; 6: 225-61$.

9 Silvestri G, Pritchard R, Welch HG. Preferences for chemotherapy in patients with advanced non-small cell lung cancer: descriptive study based on scripted interviews. BMJ 1998;317:771-5.

10 Slevin ML, Plant $H$, Lynch $D$, et al. Who should measure the quality of life, the doctor or the patient? Br J Cancer 1988;57:109-12.

11 NHS Executive. Cancer information strategy. London: NHS Executive, 2000.

12 NHS Information Authority. Toolkit for producing patient information. London: NHS Information Authority, 2002.

13 Sharma RA, Symonds RP, O'Byrne KJ, et al. Involving patients in treatment decisions: can we learn from clinical trials? Clin Oncol 2001;13:328-32.

14 CancerBACUP. Factfile. London: Lithoflow Ltd, 2001.

15 Jenkins VA, Fallowfield $\amalg$, Souhami A, et al. How do doctors explain randomised clinical trials to their patients? Eur J Cancer 1999:35:1187-93.

16 Meredith P, Emberton M, Wood C, et al. Comparison of patients' needs for information on prostate surgery with printed materials provided by surgeons. Qual Health Care 1995:4:18-23.

17 Fitzmaurice DA, Adams JL. A systematic review of patient information leaflets for hypertension. J Hum Hypertens 2000; 14:259-62.

18 Jones RB, Hampshire AJ, Tweddle S, et al. The clinician's role in meeting patient information needs: suggested learning outcomes. Med Educ 2001:35:565-71.

19 Rees CE, Ford JE, Sheard CE. Patient information leaflets for prostate cancer: which leaflets should healthcare professionals recommend? Patient Education Counseling 2003:49:263-72.

20 Conroy SP, Mayberry JF. Patient information booklets for Asian patients with ulcerative colitis. Public Health $2001 ; 115: 418-42$. 